\title{
Development of a microscopy slide system of basic subjects for inclusion in e-studies for medical and dentistry students
}

\author{
Mara Pilmane, Elga Sidhoma, Zane Vitenberga \\ Rīga Stradinš University
}

\section{INTRODUCTION}

Medical and dentistry studies are time-consuming and require patience and perseverance. The study of basic medical subjects including Histology with Cell biology and Embryology require the possibility for regular study of tissues and self-evaluation which should not be limited in time, and should not be limited to classroom time. Furthermore, official slide-sets for the abovementioned subjects often contain incomplete cell, tissue and organ slides which do not allow a full understanding of the teaching subjects. Thus, our aim was the development of a microscopy slide system for basic medical subjects to be included in e-studies which are accessible to medical students anywhere and anytime

\section{MATERIALS AND METHODS}

We planned to use 220 slides in Histology and 80 slides in Embryology. For the scanning process a Glissando Slide Scanner was used (Objective Imaging Ltd., UK). Slide images were then processed using Adobe Photoshop 7.0.1 Update and Paint.Net Software. A description of the slides was evaluated by three tutors, independent experts and IT specialists and all slides were transferred/incorporated into the Riga Stradinš University e-study system.

\section{RESULTS}

The result was the development of 786 high quality digitalised slides with easily changeable magnification for two subjects: 372 new slides for use in Histology for the Medical faculty (MF) and 290 new slides for use in Histology for the Dentistry faculty (DF); 65 new slides for use in Embryology for the MF and 59 slides for the DF. Additionally, the quality of 230 Histology slides and 99 Embryology slides previously scanned using a press scanner were improved. Furthermore, descriptions of each slide were given in Latvian and English for easier orientation and to facilitate independent study. Altogether, slide descriptions were prepared for 16 2nd semester labs and 15 3rd semester labs in MF Histology, while the DF received 14 descriptions for 1st semester labs and 8 descriptions for 2nd semester labs in this subject. In Embryology, 6 lab slide descriptions for the MF were used and $5 \mathrm{lab}$ slide descriptions for the DF were used. All slides were also marked with a special university watermark. The slideset introduction contained a warning to students regarding copy/reproduction rights. In the end, the addition of slide study to e-studies was very highly evaluated by Latvian and foreign students in student feed-back questionnaires at the end of their studies in basic medical subjects.

\section{CONCLUSION}

The inclusion of Histology and Embryology slide-sets in e-studies allows an absolutely indispensable possibility for modern, independent study in medicine, saving the time of students and tutors outside the auditorium and creates the possibility of increasing the number of students in the classes. The digitalisation of high quality slides allows the development of many variations of basic teaching slides and expands teaching explanations in this way. The existing digitalised slide-sets and their descriptions can easily be changed if needed. However, the minus of such digitalised slide-sets in e-studies is that violations of university property copy rights by students cannot be excluded.

\section{ACKNOWLEDGEMENT}

The Foundation of Boris and Inara Teterevi is highly acknowledged for its financial support of the development of digitalised e-studies slide-set Programs in Histology and Embryology at Riga Stradinš University. 